\title{
Influence of Seed Coat Color Genes on Milling Qualities of Red Lentil (Lens culinaris Medik.)
}

\author{
Maya Subedi ${ }^{1}$, Lope G. Tabil ${ }^{2}$ \& Albert Vandenberg ${ }^{1}$ \\ ${ }^{1}$ Department of Plant Sciences, University of Saskatchewan, Saskatoon, SK, Canada \\ ${ }^{2}$ Department of Chemical and Biological Engineering, University of Saskatchewan, Saskatoon, SK, Canada \\ Correspondence: Maya Subedi, Department of Plant Sciences, University of Saskatchewan, 51 Campus Drive, \\ Saskatoon, SK, S7N5A8, Canada. E-mail: mas248@mail.usask.ca
}

Received: June 12, 2018

doi:10.5539/jas.v10n10p88

\author{
Accepted: July 20, 2018 \\ Online Published: September 15, 2018 \\ URL: https://doi.org/10.5539/jas.v10n10p88
}

\begin{abstract}
Efficient milling is the key economic trait for the red lentil industry. Various seed characteristics including seed coat color can influence milling characteristics. Four basic seed coat ground colors (green, gray, tan, and brown) of 16 red lentil genotypes from a common genetic background were compared to determine the effect of seed coat color genes on three key milling quality traits: dehulling efficiency (DE), milling recovery (MR), and football recovery (FR). These genotypes were grown at two locations in Saskatchewan, Canada for two years. $\mathrm{DE}, \mathrm{MR}$, and FR results varied depending on the seed coat color conferred by specific genotypes. Green and gray seed coat color (homozygous recessive $\operatorname{tgc}$ allele) genotypes had significantly higher DE and MR percentages compared to brown or tan seed coat types (homozygous dominant $\mathrm{Tgc}$ allele) depending on genotype interaction with site-year. Seeds with brown or tan seed coats had significantly higher FR percentages in two site-years. Red cotyledon lentils with uniform shape and green or gray seed coat color might be more profitable for millers who wish to maximize DE and MR of red lentil, but brown seed coat color might be preferable in terms of FR.
\end{abstract}

Keywords: genetics, lentil, milling, quality, seed coat color

\section{Introduction}

Cultivated red lentil (Lens culinaris Medik., Fabaceae) is a good source of stable plant protein, carbohydrates, minerals, and vitamins; it is widely consumed as split cotyledons after dehulling, also known as 'milling' (Vandenberg, 2009). Milling involves removal of the seed coat, a process that results in the seed being split to produce two separated cotyledons (splits) or unsplit cotyledons (footballs), products referred to as 'dhal' (Wang, 2005; Wood et al., 2012). Dhal yield is an important post-harvest processing trait that lentil processers aim to optimize. Reduction in dhal yield and value is attributed to seeds that are not successfully dehulled, due to loss caused by chipping and abrasion. This reduction can vary according to whether genotypes are difficult or easy to dehull (Bruce, 2008; Wood et al., 2012). Significant variation with respect to dehulling has been observed among lentil genotypes (Erskine et al., 1991; Wang, 2008; Bruce, 2008), and other pulses (Singh et al., 1992; Black et al., 1998; Wood et al., 2017). Seeds of specific pulse crop genotypes can vary in shape, size, chemistry, and composition of the seed coat, including the adhesive or cohesive mechanism occurring at the interface of seed tissues. All of these factors play an important role in the efficiency of the dehulling process (Kurien, 1984; Erskine et al., 1991; Wood \& Malcolmson, 2011). Variation in percent dehulling efficiency (DE), milling recovery (MR), and football recovery (FR) has been reported among lentil cultivars, and attributed to differences in seed shape and seed coat content (Bruce, 2008; Shahin et al., 2012). An inverse relationship between amount of seed coat and milling recovery has been reported in studies of pigeon pea, lentil, and chickpea (Wang, 2008; Wood et al., 2008; Wood et al., 2017).

The thickness of seed coats can also vary depending on seed coat color and chemistry. Seeds of zero tannin lentil genotypes (homozygous tan), which have greatly reduced polyphenol content and diversity (Mirali et al., 2016) have seed coats that are about $20 \%$ thinner and about $20 \%$ less by weight than lentil genotypes with normal seed coats (Vaillancourt et al., 1986). Normal lentil genotypes (Tan) also vary with respect to seed coat color and pattern (Vandenberg \& Slinkard, 1990). Two independent genes ( $G g c$ and $T g c$ ) determine seed coat background color in lentil. Dominant and recessive combinations of the two alleles at each locus determine the four-basic 
seed coat ground colors: brown $(G g c T g c)$, gray $(G g c \operatorname{tgc})$, tan $(g g c T g c)$, and green $(g g c \operatorname{tgc})$. Differences in biochemistry, specifically the amount and types of polyphenolic compounds in the seed coat, determine the color of the seed coat in lentil. Gray and green seed coats have higher levels of flavan-3-ols, proanthocyanidins, and some flavones. The colourless proanthocyanidins can be oxidized by polyphenol oxidase, resulting in colour and structural changes (Mirali et al., 2017). The concentration of the different polyphenolic compounds can influence the dehulling process, resulting in variation in the efficiency of loosening of the seed coats from the cotyledons during milling. However, no information is currently available regarding the relationship between lentil seed coat color genes and their association with milling quality characteristics. This study compared red cotyledon lentil genotypes with green, gray, tan, and brown seed coat ground colors in terms of milling quality characteristics.

\section{Materials and Method}

\subsection{Plant Material}

Sixteen recombinant inbred lines (RILs) of red cotyledon genotypes that differ in seed coat color (4 each of green, gray, brown, and tan phenotypes) were randomly selected from the 147 lines of the LR-18 lentil RIL population (Fedoruk et al., 2013) (Table 1; Figure 1) and used to determine milling quality parameters. These lines were homogeneous in diameter and plumpness and had no seed coat pattern (Mirali et al., 2016). The parents of LR-18 are CDC Robin (small-seeded, brown seed coat with red cotyledons) and 964a-46 (large-seeded, pale green seed coat with yellow cotyledons) (Tar'an et al., 2003). The LR-18 population segregates for seed coat color independently for both alleles of the $G g c$ and $T g c$ genes.

Table 1. Homozygous genotypes and phenotypes of 16 red lentil RILs selected for analysis of milling quality

\begin{tabular}{lllllll}
\hline LR-18 RIL group & No of RILs & $\begin{array}{l}\text { Genotype at } \\
\text { Ggc locus }\end{array}$ & $\begin{array}{l}\text { Genotype at } \\
\operatorname{Tgc} \text { locus }\end{array}$ & $\begin{array}{l}\text { Seed coat color } \\
\text { phenotype }\end{array}$ & $\begin{array}{l}\text { Genotype at } \\
Y c \text { locus }\end{array}$ & $\begin{array}{l}\text { Cotyledon color } \\
\text { phenotype }\end{array}$ \\
\hline 1 & 4 & $G g c G g c$ & $\operatorname{TgcTgc}$ & Brown & $Y c$ & Red \\
2 & 4 & $G g c G g c$ & $\operatorname{tg} \operatorname{tgc}$ & Gray & $Y c$ & Red \\
3 & 4 & ggc $g g c$ & $\operatorname{Tgc} T g c$ & Tan & $Y c$ & Red \\
4 & 4 & $g g c g g c$ & $\operatorname{tgctgc}$ & Green & $Y c$ & Red \\
\hline
\end{tabular}

Note. RIL: Recombinant inbred line.

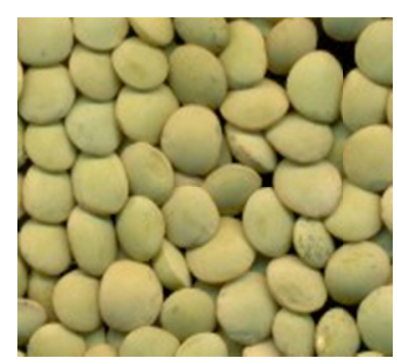

Green $(g g c \operatorname{tgc})$

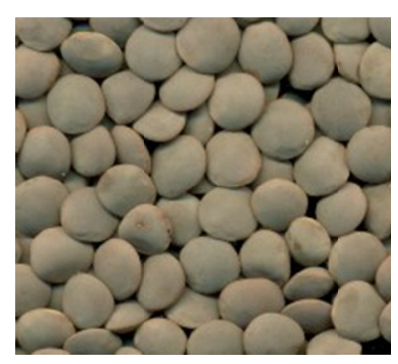

Gray $(G g c t g c)$

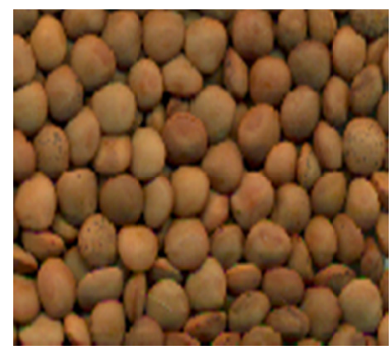

$\operatorname{Tan}(g g c \operatorname{Tgc})$

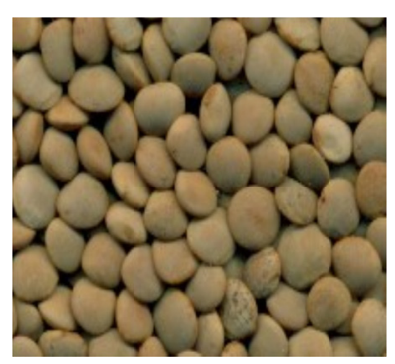

Brown $(G g c T g c)$

Figure 1. Representative samples of the four- basic seed coat ground color phenotypes and genotypes of lentil

\subsection{Field Experiments and Environmental Conditions}

The 16 selected lines were grown in three replicates in a randomized complete block design at two locations in Saskatchewan, the Saskatchewan Pulse Growers farm (SPG; $52.05^{\circ} \mathrm{N}, 106.41^{\circ} \mathrm{W}$ ) and the University of Saskatchewan experimental farm in Sutherland $\left(52.14^{\circ} \mathrm{N}, 106.61^{\circ} \mathrm{W}\right)$ in 2013 and 2014. The plots were sown May 13 and May 14 at Sutherland and May 28 and June 3 at SPG, respectively, in 2013 and 2014 at a rate of 130 seeds $/ \mathrm{m}^{2}$ in $1 \mathrm{~m}^{2}$ microplots. Individual microplots were hand harvested when $95 \%$ of the lower canopy pods had turned yellow to brown in color. Complete site details and cultivation practices are described in Table 2 . 
Table 2. Site description and cultivation practices employed in the experimental trials at Sutherland and SPG in 2013 and 2014

\begin{tabular}{lll}
\hline Soil properties/cultivation practices & Sutherland & SPG \\
\hline Soil pH & $6.0-6.6$ & $7.4-7.6$ \\
Organic matter content (\%) & $3.2-3.6$ & $4.0-4.3$ \\
Soil type & Clay loam & Loam \\
Soil zone & Dark brown & Dark brown \\
Sowing date & May 13, 2013; May 14, 2014 & May 28, 2013; June 3, 2014 \\
First bloom & $2^{\text {nd }}$ to $3^{\text {rd }}$ week of June & $3^{\text {rd }}$ to 4 $4^{\text {th }}$ week of June \\
Harvesting time & $1^{\text {st }}$ week of September & $2^{\text {nd }}$ week of September \\
\hline
\end{tabular}

Note. SPG: Saskatchewan Pulse Growers experimental field.

Mean temperature and total monthly precipitation data for each month of the growing season at Saskatoon, Saskatchewan for both years were obtained from Environment Canada (2014) (Table 3).

Table 3. Mean daily temperature $\left({ }^{\circ} \mathrm{C}\right)$ and total monthly precipitation $(\mathrm{mm})$ for the 2013 and 2014 growing seasons at Saskatoon, Saskatchewan, Canada

\begin{tabular}{|c|c|c|c|c|c|c|c|c|c|c|}
\hline \multirow{2}{*}{ Climate/Month details } & \multicolumn{2}{|c|}{ May } & \multicolumn{2}{|c|}{ June } & \multicolumn{2}{|c|}{ July } & \multicolumn{2}{|c|}{ Aug } & \multicolumn{2}{|c|}{ Sept } \\
\hline & 2013 & 2014 & 2013 & 2014 & 2013 & 2014 & 2013 & 2014 & 2013 & 2014 \\
\hline Temperature $\left({ }^{\circ} \mathrm{C}\right)$ & 13.0 & 10.1 & 15.5 & 14.1 & 17.4 & 18.3 & 18.9 & 17.9 & 15.2 & 12.4 \\
\hline Precipitation (mm) & 15.9 & 61.1 & 117.7 & 94.8 & 35.6 & 44.5 & 14.9 & 18.5 & 15.4 & 10.7 \\
\hline
\end{tabular}

Source: http://climate.weather.gc.ca/climate_data/daily_data_e.html?StationID $=47707$

\subsection{Measurement of Milling Quality Characteristics}

Milling quality traits were determined using a previously described procedure (Subedi et al., 2017). Briefly, $30 \mathrm{~g}$ uniformly dried seed samples were tempered overnight to $12.5 \%$ moisture and then dehulled using a grain testing mill (TM05, Satake Engineering Co., Hiroshima, Japan) fitted with a 36-mesh abrasive wheel rotating at 1100 rpm for $38 \mathrm{~s}$ (Wang, 2005). After dehulling, milled seed samples were passed through a series of slotted and round sieves to separate football and split fractions. All fractions were weighed and expressed as a proportion of the total original milled sample (Wang, 2005; Bruce, 2008). Whole lentils remaining over the slotted sieve were considered football, lentils remaining in the round sieve were considered split, any whole and split lentils with adhering hulls were separated manually into their respective adhering hulled or dehulled classes. All fractions were weighed and then expressed as a proportion of the total original milled sample weight. Dehulling efficiency (DE) was defined as the percent of un-dehulled whole and split seed percentage relative to total seed sample weight; milling recovery (MR) was the percent of dehulled splits and football fractions relative to total seed sample weight; football recovery (FR) was the percent of dehulled football fraction to total seed sample weight. All parameters were calculated using the following formulas mentioned in (Subedi et al., 2018):

$$
\begin{gathered}
\text { Dehulling efficiency }(D E)=\left[1-\frac{W U \text { whole }+ \text { WUsplit }}{W \text { Sample }}\right] \times 100 \\
\text { Milling recovery }(M R)=\frac{W \text { milled }}{W \text { Sample }} \\
\text { Football Recovery }(F R)=\frac{\text { Wootball }}{W \text { Sample }}
\end{gathered}
$$

where, WUwhole is the weight of undehulled whole seeds (in g), WUsplit is weight of undehulled split seeds (in g), Wsample is the weight of the seed sample, Wmilled is the total weight of milled seeds (the weight of dehulled whole seeds plus the weight of dehulled split seeds in g), and Wfootball is the weight of footballs (dehulled whole seeds, in g). Dehulling efficiency, milling recovery, and football recovery are expressed as percentages.

\subsection{Data Analysis}

The location and year of the field trials were treated as environments (site-years). Analysis of variance (ANOVA) was performed using the MIXED procedure of SAS 9.4 (SAS Institute, Inc., 2015). Homogeneity and normality were checked before subjecting data to ANOVA. For the best fit model in the combined analysis, genotype group (seed color type) and site year were considered fixed and replications nested within site-years were considered random effects. Heterogeneous variance structures were modeled using the repeated/group statement with mixed models wherever required. Table 4 shows the $P$-values from the mixed model ANOVA F-test for the response 
variables. Site-year had a significant effect $(P=0.001)$ on $\mathrm{DE}, \mathrm{MR}$, and FR and, therefore, these data were analyzed separately for each site-year. Least squared means were computed for fixed effects using the LSMEANS statement. Significance of variance was declared at $P<0.01$ and $P<0.001$. Means were separated using Fisher's least significant difference (LSD) at $P<0.05$. Graphs were plotted using SigmaPlot V2 (SigmaPlot, 2010).

Table 4. P values from mixed model ANOVA F-test results for the effect of seed coat color, site year, and seed coat color by site year interaction on dehulling efficiency, milling recovery, and football recovery at SPG and Sutherland, Saskatoon, SK in 2013 and 2014

\begin{tabular}{lllll}
\hline \multirow{2}{*}{ Source of variation } & \multirow{2}{*}{ df } & \multicolumn{3}{c}{ P values } \\
\cline { 3 - 5 } & & Dehulling efficiency & Milling recovery & Football recovery \\
\hline Seed coat color & 3 & $<0.000^{* * *}$ & $0.010^{* *}$ & $0.001^{* * *}$ \\
Site-year & 3 & $<0.000^{* * *}$ & $<0.000^{* * *}$ & $<0.000^{* * *}$ \\
Seed coat color $\times$ site-year & 9 & 0.066 & 0.070 & $0.006^{* *}$ \\
\hline
\end{tabular}

Note. ${ }^{* *}$ and $* * *$ denote significance at $P<0.01$ and 0.001 , respectively. df indicates degrees of freedom.

\section{Results}

\subsection{Effect of Seed Coat Color on Dehulling Efficiency (\%)}

Results from all environments showed highly significant differences $(P<0.001)$ for DE values among lentil genotypes with different seed coat ground color (Table 5).

Table 5. P-values from mixed model ANOVA F-test for the fixed effect of seed coat color on milling quality traits for four site-years (Sutherland and SPG, SK in 2013 and 2014)

\begin{tabular}{llllll}
\hline Site-year & Source of variation & df & Dehulling efficiency & Milling recovery & Football recovery \\
\hline Sutherland 2013 & Seed coat color & 3 & $0.006^{* *}$ & $0.007^{* *}$ & $0.005^{* *}$ \\
SPG 2013 & Seed coat color & 3 & $0.001^{* * *}$ & $0.000^{* * *}$ & $0.001^{* *}$ \\
Sutherland 2014 & Seed coat color & 3 & $0.000^{* * *}$ & $0.000^{* * *}$ & 0.886 \\
SPG 2014 & Seed coat color & 3 & $0.002^{* *}$ & $0.003^{* *}$ & 0.656 \\
\hline
\end{tabular}

Note. ${ }^{* *}$ and $* * *$ denote significance at $P<0.01$ and 0.001 , respectively. df indicates degrees of freedom. 


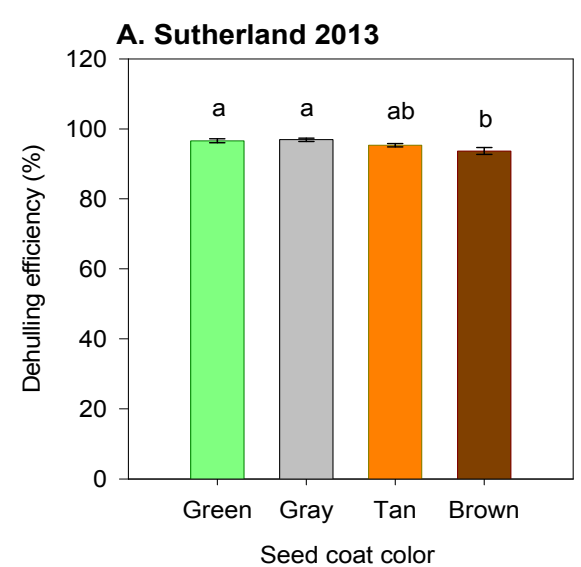

C. SPG 2013

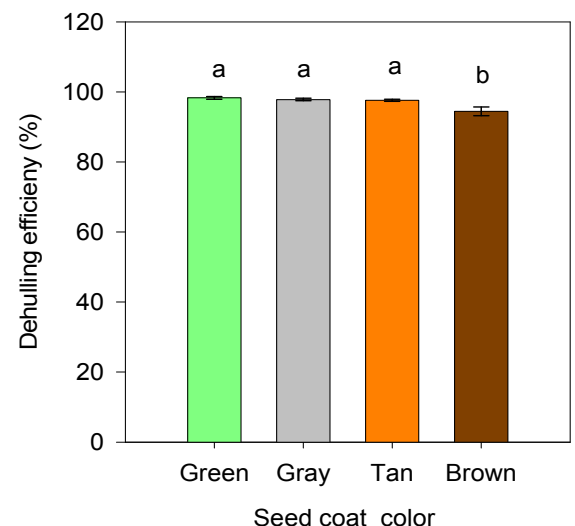

\section{B. Sutherland 2014}

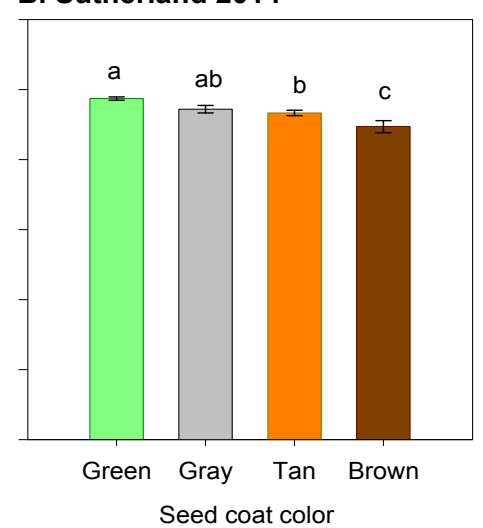

D. SPG 2014

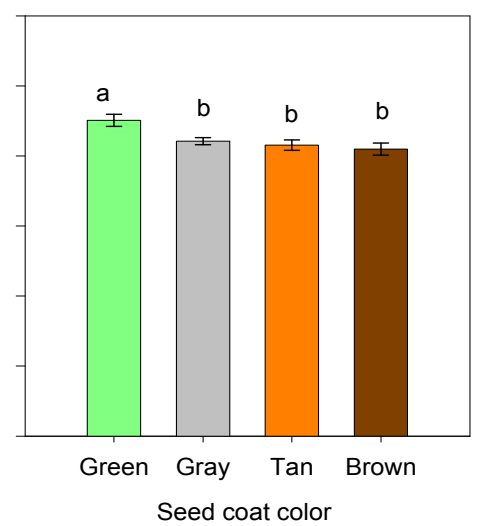

Figure 2. Mean dehulling efficiency (\%) of four lentil seed coat color phenotypes (green, gray, tan, and brown) at Sutherland (A and B) and SPG (C and D) sites, SK in 2013 (A and C) and 2014 (B and D)

Note. Error bars are standard error of replicates in each site-year. Means with similar letters above the bars indicate no significant difference between seed coat color groups at $\mathrm{LSD}_{0.05}$ (Sutherland $2013=1.9$; Sutherland $2014=3.2 ;$ SPG $2013=1.89 ;$ SPG $2014=4.3$ ).

\subsection{Effect of Seed Coat Color on Milling Recovery (\%)}

Results for MR showed significant differences $(P<0.001)$ among lentil genotypes with different seed coat colors at all locations and years (Table 5$)$. The brown seed coat color genotypes had significantly lower $(P<$ 0.001 ) MR values compared to green, gray, and tan color genotypes in four site-years. In SPG 2014, brown seed coat genotypes displayed significantly $(P<0.05)$ lower MR values than green seed coat color genotypes but were not different than gray or tan genotypes (Figure 3). 

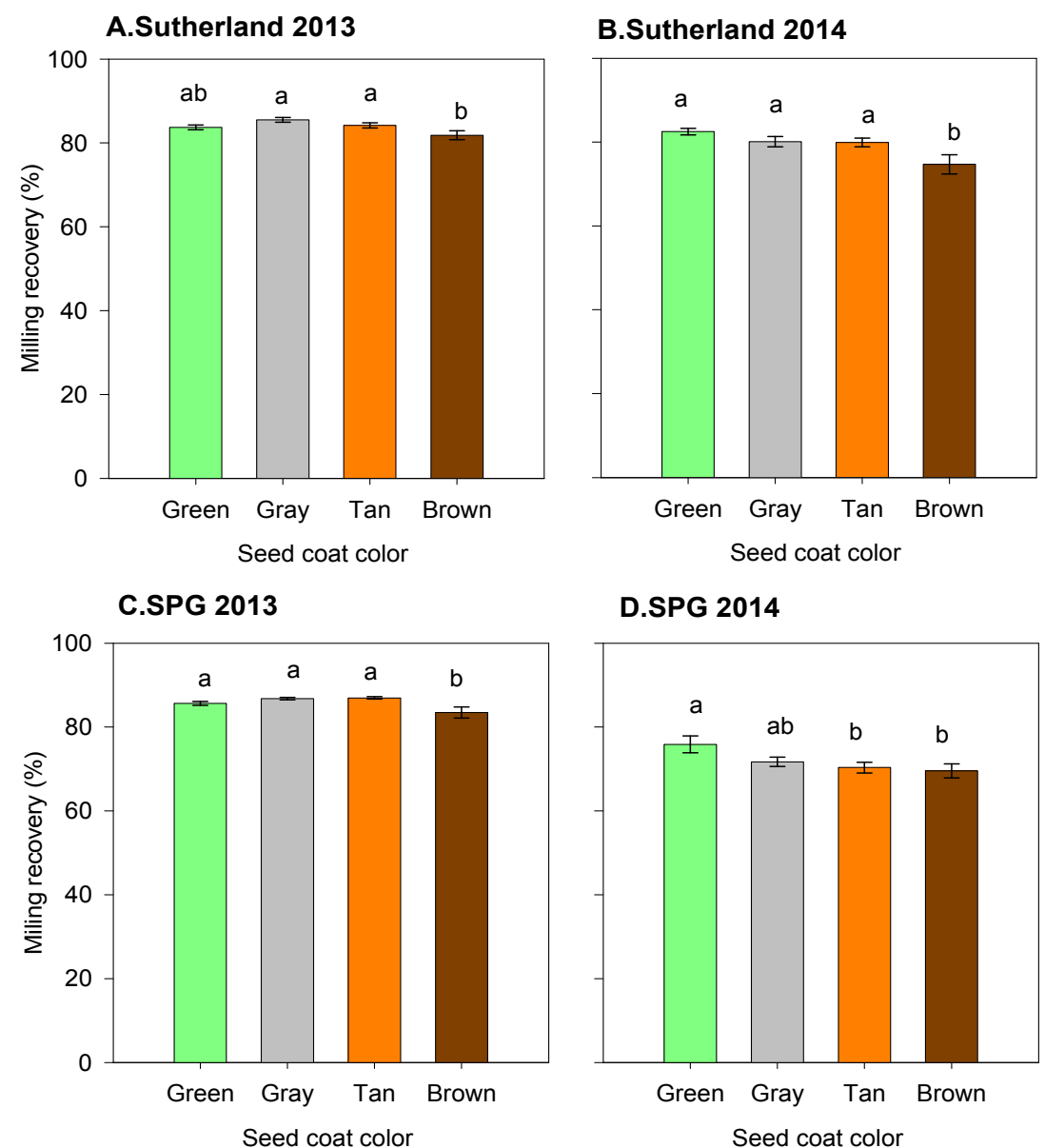

\section{D.SPG 2014}

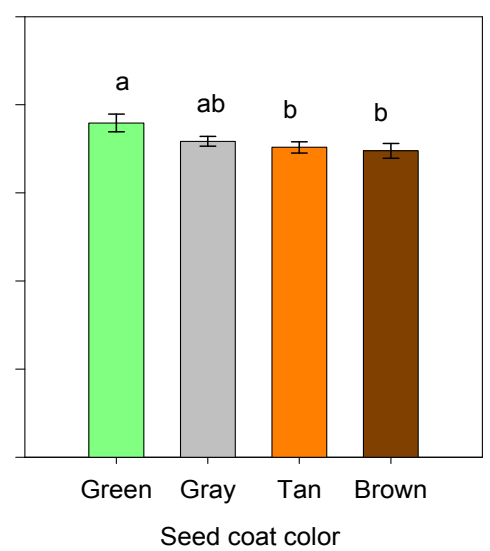

Figure 3. Mean milling recovery (\%) of four lentil seed coat color phenotypes (green, gray, tan, and brown) at Sutherland (A and B) and SPG (C and D) sites, SK in 2013 (A and C) and 2014 (B and D)

Note. Error bars are standard errors for three replicates of each type in each site-year. Means with similar letters above the bars indicate no significant differences between phenotype at $\mathrm{LSD}_{0.05}$ (for Sutherland $2013=2.00$; Sutherland $2014=4.2$; SPG $2013=2.1$; SPG $2014=4.5$ ). LSD denotes Fisher's least significant difference.

\subsection{Effect of Seed Coat Color on Football Recovery (\%)}

Genotypes with different seed coat colors had significantly different $(P<0.001)$ FR at both sites in 2013 but not in 2014 (Table 4). Tan $(g g c T g c)$ and brown seed coat $(G g c T g c)$ color genotypes had significantly higher (15$20 \%$ higher $(P<0.001)$ FR than green seed coat color genotypes at both sites in 2013 (Figure 4). Gray color $(G g c t g c)$ genotypes had significantly $(P<0.05)$ lower FR than the tan and brown genotypes in SPG 2013 but had similar FR to green seed coat genotypes in both site-years (Figure 4). 
A. Sutherland 2013

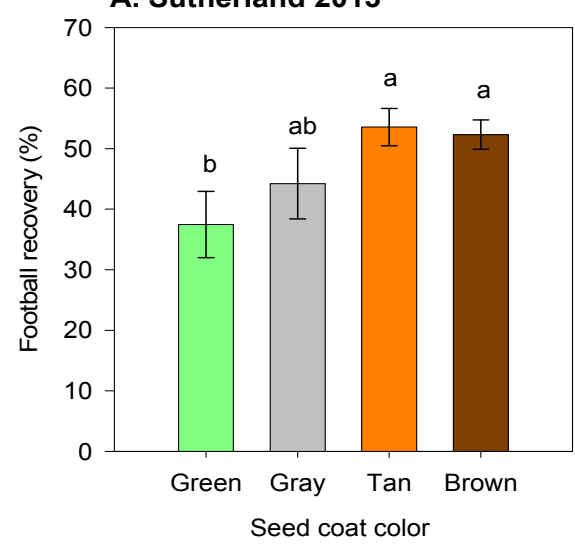

B. SPG 2013

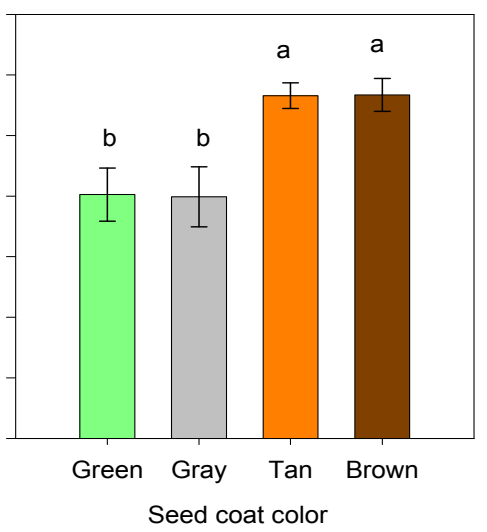

Figure 4. Mean football recovery (\%) of four lentil seed coat color phenotypes (green, gray, tan, and brown) at Sutherland (A) and SPG (B) sites, SK in 2013

Note. Error bar are standard errors for three replicates of each type in each site-year. Means with similar letters above bars indicate no significant differences between phenotype groups at $\operatorname{LSD}_{0.05}$ (Sutherland 2013=12.7; SPG $2013=11.4)$.

\section{Discussion}

Milling quality is a key economic trait for the red lentil market class. Effects of genetic and crop management factors on lentil milling quality are poorly understood. We compared milling quality parameters (DE, MR, and FR) of four basic seed coat ground colors conferred by specific genes. To our knowledge, this is the first report on influence of seed coat color genes on milling quality in lentil.

Our results show that both green $(g g c t g c)$ and gray $(G g c t g c)$ genotypes had significantly greater DE $(8-10 \%$ higher) and MR (5-8\% higher) than brown $(G g c T g c)$ seed coat color genotypes depending on the site-year. Gray and green seed coats are homozygous for the recessive $\operatorname{tgc}$ allele, whereas the brown seed coat is homozygous for the dominant allele $(T g c)$. This indicates that DE and MR percentages are highly influenced by the $\tan (\operatorname{tgc})$ seed coat color gene. The higher MR and DE for green and gray seed coat phenotypes could be the result of differences in seed coat color chemistry. LR-18 RILs with green or gray seed coats, which express the homozygous $\operatorname{tgc}$ allele, have higher amounts of flavan-3-ols, proanthocyanins, and some flavanol groups compared to other seed coat phenotypes (Mirali et al., 2017). The proanthocyanin group of phenolic compounds are basically colorless (Lepiniec et al., 2006; Marles et al., 2003); and might make gray and green seed coats more transparent compared to brown seed coats in lentil (Mirali et al., 2017). These transparent seed coats might be thinner than the opaque types, possibly affecting their ability to absorb and release moisture. Therefore, lentil with green or gray seed coats may be easier to loosen from the cotyledons during abrasive dehulling. We did not specifically collect data related to thickness of seed coat of these genotypes, but several researchers (Kurien, 1984; Wang, 2008; Wood et al., 2008) have observed an inverse relationship between the amount of seed coat and efficient milling recovery in other pulses. Other studies have noted that white color seed coats are thinner than black seed coats in lima bean (Phaseolus lunatus L) due to shorter cells in the palisade layer (Kannenberg \& Allard, 1964); white seeded common bean genotypes are deficient in polyphenols (Golam Masum Akond, 2011); and differences in the thickness of seed coat palisade cell layers caused different capacities for water imbibition in two lima bean lines (Agbo et al., 1986).

Rapid and smooth imbibition of seeds during conditioning is essential for dehulling of lentil (Wang, 2005). The lower DE and MR of brown seed coat genotypes noted in our study is consistent with a milling efficiency study in which brown seed coat lentil cultivars (CDC Robin and CDC Imperial) produced lower DE and MR values (Bruce, 2008). The genotypes used in our study had CDC Robin as a parent. We observed significant reduction of DE and MR values of all seed coat color groups at both sites in 2014 compared to 2013. This could be attributable to weather variability between the two growing years, particularly more seasonal moisture (157.8 $\mathrm{mm}$ ) in the second half of the 2014 growing season (Table 2), because wet environments cause lentil cultivars to have reduced DE and MR (Bruce, 2008). Moreover, the 2014 plots were affected by stemphylium blight (SB) caused by Stemphylium botryosum. This disease might also have lowered DE and MR values because disease-infected seeds become misshapen and have stained seed coats (Caudillo-Ruiz, 2016). In the current study, 
the magnitude of the reduction of DE and MR percentages was high for brown seed coat phenotypes compared to other seed coat colors, indicating that lentils with brown seed coats might be more susceptible to damage due to wet conditions. This is supported by reports that seed coat color has a large impact on weathering ability of lentil seeds and that gray seed coat lentil genotypes can better withstand unfavourable wet weather relative to brown seed coat lentil genotypes (Bruce, 2008). Seed coat color is significantly associated with physical and chemical characteristics that affect the weathering ability of common bean (Phaseolus vulgaris L.) (Beninger et al., 1998). Darkening of seed coat color in pinto beans is associated with biochemical changes in the seed coat and controlled by a single gene $(S d)$; darkening is dominant to slow darkening but modifying genes and the environment affect the extent of darkening in both genotypes (Junk-Knievel et al., 2008).

In this study, lentils with both brown and tan seed coat color phenotypes only had significantly greater FR (15-20\%) compared to green or gray seed coat colors in the 2013 season. This might be due to both brown and tan genotypes having more opaque seed coats than green or gray due to presence of dense polyphenolic compounds (Mirali et al., 2017). The presence of dense polyphenolic compounds makes seeds harder and more difficult to split during the milling processes, as noted for pigeon pea (Cajanus cajan) and kidney bean (Singh et al., 1992; Reichert et al., 1984). Lentil genotypes with brown or tan seed coats might also absorb more moisture through the seed coat into cotyledon tissues, resulting in increased adherence between the cotyledons that results in less splitting during the milling process. Green or gray seed coat genotypes could also have different hygroscopic properties that influence moisture absorption and transmission through cotyledonary tissues. This is supported by the finding that brown lentil cultivars produce a significantly higher FR portion if harvested in wet weather conditions (Bruce, 2008).

Inconsistency of FR values among genotypes across site-years in our results might also be an indication that FR is more sensitive to the growing environment compared to other milling traits. Significant differences in FR among seed coat color groups were only observed in dry and optimal weather, aligning with previous milling efficiency results in lentil (Bruce, 2008). This suggests that, given the typical optimal harvest weather in Saskatchewan, lentil millers might develop a preference for specific red lentil cultivars with brown or tan seed coats if they wish to maximize football recovery. At the commercial scale, stone separation, roller speed, and other milling configurations could be adjusted based on seed coat surface, texture, or seed thickness; investigating these aspects was not possible at the lab scale using our Satake dehuller. Genotypes with brown or tan seed coat colors and harvested under optimal conditions produced higher FR values for the techniques and instruments used in this study.

Overall, the findings from this study suggest that the red lentil milling industry in northern temperate climatic zones might be able to increase DE and MR recovery by using red lentils that have green or gray seed coat color. Green and gray seed coats contain beneficial polyphenolic compounds such as proanthocyanin oligomers and some flavanols (Mirali et al., 2017). These compounds have higher antioxidant capacity (Dueñas et al., 2006) and additional economic value could be achievable from use of the seed coats. One tonne of milled lentil can provide $80-110 \mathrm{~kg}$ of seed coats (Dueñas et al., 2002); if, 9-22\% seed coat-methanol-water extract can be extracted (i.e., 7-24 kg extract) from the seed coats (Ronzio et al., 1998), this represents 0.7-2.4 kg of phenolic compounds that can be obtained. Therefore, lentil seed coat extract could have potential as a source of plant-based antioxidants. Uses for this source of natural antioxidants from lentil seed coats could be developed for fortified foods and nutraceuticals.

In contrast, if millers wish to maximize FR, they could choose red lentils with either brown or tan seed coats. Therefore, future red lentil breeding program objectives could focus on the development of red cotyledon varieties with green or gray background color combined with resistance to SB to achieve higher MR and DE. For specific niche markets requiring higher FR, cultivars with brown or tan seed coats might be more suitable. The study findings also suggest that higher seasonal precipitation during the seed filling period may result in the development of seed coat characteristics that are less desirable in terms of milling quality.

\section{Conclusions}

Analysis of the effects of the four basic seed coat background colors of red lentil on milling characteristics indicated that seed coat color influences DE, MR, and FR. Genotypes that express the homozygous recessive tgc allele (green and gray seed coats) produced the highest values of DE and MR. This suggests that milling lentils with green or gray seed coats might be more profitable for millers who wish to maximize total milling recovery yield for lentils. For maximizing FR, brown or tan seed coat color genotypes might be preferable under optimal weather conditions; however, inconsistent results of FR analysis suggest the need for further research to confirm this finding under a wider range of conditions. 


\section{References}

Agbo, G. N., Uebersax, M. A., Hosfield, G. L., \& Markakis, P. (1986). Water uptake and flour gelatinization of three dry bean cultivars (Phaseolus vulgaris L.). Journal of Food Science, 51, 850-851. https://doi.org/ 10.1111/j.1365-2621.1986.tb13953.x

Beninger, C. W., Hosfield, G. L., \& Muraleedharan, G. N. (1998). Physical characteristics of dry beans in relation to seed coat color genotype. Horticulture Science, 33(2), 328-329.

Black, R. G., Singh, U., \& Meares, C. (1998). Effect of genotype and pre-treatment of field peas (Pisum sativum) on their dehulling and cooking quality. Journal of the Science of Food and Agriculture, 77, 251-258. https://doi.org/10.1002/(SICI)1097-0010(199806)77:2<251:AID-JSFA31>3.0.CO;2-S

Bruce, J. (2008). The effect of pre-harvest treatments on the milling efficiency of red lentil (MSc Thesis, University of Saskatchewan, Saskatoon, Canada).

Caudillo-Ruiz, K. B. (2016). Characterization of the stemphylium blight pathogens and their effect on lentil yield (MSc Thesis, University of Saskatchewan, Saskatoon, Canada).

Dueñas, M., Hernández, T., \& Estrella, I. (2002). Phenolic composition of the cotyledon and the seed coat of lentils (Lens culinaris L.). European Food Research and Technology, 215, 478-483. https://doi.org/10.1007/ s00217-002-0603-1

Dueñas, M., Hernández, T., \& Estrella, I. (2006). Assessment of in vitro antioxidant capacity of the seed coat and the cotyledon of legumes in relation to their phenolic contents. Food Chemistry, 98(1), 95-103. https://doi.org/10.1016/j.foodchem.2005.05.052

Environment Canada. (2014). Historical climate data. Government of Canada, Ottawa, ON. Retrieved March 21, 2018, from http://climate.weather.gc.ca/climate_data/daily_data_e.html?StationID=47707

Erskine, W., Williams, P. C., \& Nakkoul, H. (1991). Splitting and dehulling lentil (Lens culinaris): Effects of genotype and location. Journal of the Science and Food Agriculture, 57(1), 85-92. https://doi.org/10.1002/ jsfa.2740570110

Fedoruk, M. J., Vandenberg, A., \& Bett K. E. (2013). Quantitative trait loci analysis of seed quality characteristics in lentil using single nucleotide polymorphism markers. The Plant Genome, $6,3$. https://doi.org/10.3835/plantgenome2013.05.0012

Golam Masum Akond, A. S. M., Khandaker, L., Berthold, J., Gates, L., Peters, K., Delong, H., \& Hossain, K. (2011). Anthocyanin, total polyphenols, and antioxidant activity of common bean. American Journal of Food and Technology, 6, 385-394. https://doi.org/10.3923/ajft.2011.385.394

Junk-Knievel, D. C., Vandenberg, A., \& Bett, K. E. (2008). Slow darkening in pinto bean (Phaseolus vulgaris L.) seed coats is controlled by a single major gene. Crop Science, 48, 189-193. https://doi.org/10.2135/ cropsci2007.04.0227

Kannenberg, L. W., \& Allard, R. W. (1964). An association between pigment and lignin formation in the seed coat of the lima bean. Crop Science, 4, 621-622. https://doi.org/10.2135/cropsci1964.0011183X0004000 $60021 x$

Kurien, P. P. (1984). Dehulling technology of pulses. Research Industry, 29(3), 207-214.

Lepiniec, L., Debeaujon, I., Routaboul, J. M., Baudry, A., Pourcel, L., Nesi, N., \& Caboche, M. (2006). Genetics, and biochemistry of seed flavonoids. Annual Review of Plant Biology, 57, 405-430. http://doi.org/10.1146/ annurevarplant.57.032905.105252

Marles, M. A., Ray, H., \& Gruber, M. Y. (2003). New perspectives on proanthocyanidins biochemistry and molecular regulation. Phytochemistry, 64(2), 367-383. https://doi.org/10.1016/S0031-9422(03)00377-7

Mirali, M., Purves, R. W., \& Vandenberg, A. (2017). Profiling the phenolic compounds of the four major seed coat types and their relation to color genes in lentil. Journal of Natural Products, 80(5), 1310-1317. https://doi.org/10.1021/acs.jnatprod.6b00872

Mirali, M., Purves, R. W., Stonehouse, R., Song, R., Bett, K., \& Vandenberg, A. (2016). Genetics and biochemistry of zero-tannin lentils. PLoS One, 11(10), e0164624. https://doi.org/10.1371/journal.pone. 0164624

Reichert, R. D., Oomah, B. D., \& Youngs, C. G. (1984). Factors affecting the efficiency of abrasive-type dehulling of grain legumes investigated with a new intermediate-sized, batch dehuller. Journal of Food 
Science, 49, 267-272. https://doi.org/10.1111/j.1365-2621.1984.tb13723.x

Ronzio, R. A., Muanza, D. N., \& Sparks, W. S. (1998). Antioxidant derived from lentil and its preparation and uses. Google Patents. Retrieved from https://patents.google.com/patent/US5762936

SAS Institute, Inc. (2015). SAS/STATR 13.2 User's Guide. Cary, NC: SAS Institute, Inc. Retrieved February 20, 2015, from https://support.sas.com/documentation/cdl/en/stathpug/67524/PDF/default/stathpug.pdf

Shahin, M. A., Symons, S. J., \& Wang, N. (2012). Predicting dehulling efficiency of lentils based on seed size and shape characteristics measured with image analysis. Quality Assurance and Safety of Crops and Foods, 4, 9-16. https://doi.org/10.1111/j.1757-837X.2011.00119.x

SigmaPlot. (2010). SigmaPlot V10 [Systat Software]. San Jose, CA, USA.

Singh, U., Santosa, B. A. S., \& Rao, P. V. (1992). Effect of dehulling methods and physical characteristics of grain on dhal yield of pigeon pea (Cajanus cajan L.) genotypes. International Journal of Food Science and Technology, 29(6), 350-353.

Subedi, M., Bett, K. E., Khazaei, H., \& Vandenberg, A. (2018). Genetic mapping of milling quality traits in lentil (Lens culinaris Medik). The Plant Genome, 11. https://doi.org/10.3835/plantgenome2017.10.0092

Subedi, M., Willenborg, C. J., \& Vandenberg, A. (2017). Influence of harvest aid herbicides on seed germination, seedling vigor and milling quality traits of red lentil (Lens culinaris L.). Frontiers in Plant Science, 8, 311. https://doi.org/10.3389/fpls.2017.00311

Tar'an, B., Buchwaldt, L., Tullu, A., Banniza, S., Warkentin, T. D., \& Vandenberg, A. (2003). Using molecular markers to pyramid genes for resistance to ascochyta blight and anthracnose in lentil (Lens culinaris Medik.). Euphytica, 134(2), 223-230. https://doi.org/10.1023/B:EUPH.0000003913.39616.fd

Vaillancourt, R., Slinkard, A. E., \& Reichert, R. D. (1986). The inheritance of condensed tannin concentration in lentil. Canadian Journal of Plant Science, 66(2), 241-246. https://doi.org/10.4141/cjps86-038

Vandenberg, A. (2009). Postharvest processing and value addition. In W. Erskine \& F. J. Muehlbauer (Eds.), The lentil: botany, production and uses (pp. 391-424). CAB International. https://doi.org/10.1079/9781845 934873.0391

Vandenberg, A., \& Slinkard, A. E. (1990). Genetics of seed coat color and pattern in lentil. Journal of Heredity, 81(6), 484-488. https://doi.org/10.1093/oxfordjournals.jhered.a111030

Wang, N. (2005). Optimization of a laboratory dehulling process for lentil (Lens culinaris). Cereal Chemistry, 82, 671-676. https://doi.org/10.1094/CC-82-0671

Wang, N. (2008). Effect of variety and crude protein content on dehulling quality and on the resulting chemical composition of red lentil (Lens culinaris). Journal of the Science of Food and Agriculture, 88, 885-890. https://doi.org/10.1002/jsfa.3165

Wood, J. A., \& Malcolmson L. J. (2011). Pulse milling technologies. In B. Tiwari, A. Gowen, \& B. McKenna (Eds.), Pulse foods: Processing, quality, and nutraceutical applications (pp. 193-221). Academic Press, UK. https://doi.org/10.1016/B978-0-12-382018-1.00008-3

Wood, J. A., Knights, E. J., \& Harden, S. (2008). Milling performance in desi-type chickpea (Cicer arietinum L.): Effects of genotype, environment, and seed size. Journal of the Science of Food and Agriculture, 88, 108-115. https://doi.org/10.1002/jsfa.3053

Wood, J. A., Knights, E. J., Campbell, G. M., \& Choct, M. (2012). Milling performance and other quality traits affected by seed shape in isogenic lines of desi chickpea (Cicer arietinum L.). Journal of Agricultural Science, 4(10), 244-289. https://doi.org/10.5539/jas.v4n10p244

Wood, J. A., Knights, E. J., Campbell, G. M., \& Choct, M. (2017). Near-isogenic lines of desi chickpea (Cicer arietinum L.) that differ in milling ease: Differences in chemical composition. Journal of Food Science and Technology, 54(4), 1002-1013. https://doi.org/10.1007/s13197-016-2483-6

\section{Copyrights}

Copyright for this article is retained by the author(s), with first publication rights granted to the journal.

This is an open-access article distributed under the terms and conditions of the Creative Commons Attribution license (http://creativecommons.org/licenses/by/4.0/). 